\section{Analise e avaliação de um secador pneumático de fluxo concorrente com carga, revolvimento e descarga pneumáticos}

ISSN

1809-9475

\section{Analysis and evaluation of a pneumatic dryer flow concurrent with load and unloading pneumatic revolving}

Fernanda Augusta de Oliveira Melo ${ }^{1}$

Juarez Sousa Silva ${ }^{2}$

Roberto Precci Lopes ${ }^{3}$

\section{Palavras-chave:}

Secagem mecânica

Transporte

Pneumático

Fluxo Concorrente

\section{Artigo \\ Original \\ Original \\ Paper}

Recebido em 11/2012

Aprovado em 08/2013

\section{Resumo}

O presente trabalho teve por objetivo analisar e avaliar um secador de fluxos concorrentes com carga, revolvimento e descarga pneumáticos, compatível com a produção e a capacidade de investimento da pequena produção para a secagem de café pergaminho. $\mathrm{O}$ experimento foi realizado no Setor de Pré-processante e Armazenamento de Produtos Vegetais (DEA/UFV). Foram realizados quatro testes, sendo três com o secador operando com carga máxima e um com carga reduzida. Para análise do sistema de secagem foi utilizada a metodologia proposta por Bakker-Arkema et al. com os padrões propostos por Silva et al. Com os dados obtidos, o secador desenvolvido mostrou-se eficiente energeticamente, apresentando baixo consumo específico de energia; fácil de ser operando durante o carregamento, secagem e descarga, exigindo pouca manutenção e mão-de-obra; e funciona com quantidade de café disponível.

\begin{abstract}
The objective of the present work was to analyze and evaluate a concurrent flow dryer with pneumatic load, rotation, and discharge, compatible with the production and the investment capacity of a small production for the drying of parchment coffee. The experiment was conducted in the Sector of Pre-Processing and Storage of Plant Products (DEA-UFV). Four tests were conducted, three with the dryer operating at full load, and one with the dryer operating at a reduced load. In the analysis of the system, a methodology proposed by Bakker-Arkema et al. was used, with the standards proposed by Silva et al.. With the data obtained, the dryer developed proved to be energy efficient, presenting low consumption of energy; easy operation during loading, drying, and discharge, requiring little maintenance and labor; and it works with the quantity of coffee available.
\end{abstract}

Keywords:

Mechanical drying

Pneumatic transport

Concurrent flow

\footnotetext{
${ }^{1}$ Docente dos Cursos Engenharia Ambiental, Engenharia de Produção, Gestão de Recursos Humanos e Ciências Contábeis do UniFOA, D. S. Engenharia Agrícola pela UFV.

${ }^{2}$ Professor do Curso de Engenharia Agrícola da UFV, PhD pela Michigan State University, Estados Unidos

${ }^{3}$ Professor do Curso de Engenharia Agrícola da UFV, D. S. Engenharia Agrícola pela UFV
} 


\section{Introdução}

O aumento do preço dos fatores de produção e insumos agrícolas, aliados às oscilações constantes no preço do café, tem ocasionado, nos últimos anos, queda na renda e na competitividade da cafeicultura. Para superar esse problema, os cafeicultores buscam novas tecnologias, com o objetivo de aumentar a produtividade e de melhorar a qualidade do produto.

A secagem artificial do café, em secadores mecânicos, é considerada de muita importância por agilizar a colheita e, principalmente, por independer das condições climáticas.

Apesar de ser, economicamente, mais viável que o método de terreiros que muitos, erroneamente, consideram como uma tecnologia de baixo custo, o custo inicial para a instalação de um secador mecânico, aliado à exigência de algum conhecimento técnico, dificulta a adoção do sistema pelos pequenos produtores, que são responsáveis por grande parte da produção nacional (MACHADO et al., 2003b).

Um dos problemas encontrados no processo de secagem artificial de café reside no fato de a operação ser realizada em secadores projetados para outros grãos e adaptados para a secagem de café, resultando em alto custo operacional e em baixa eficiência energética (Pinto Filho, 1994; Sampaio, 2004). Além disso, o tamanho dos secadores não é compatível com a quantidade produzida pelo pequeno cafeicultor. No caso de desenvolvimento ou adaptação de secadores para atender as necessidades de secagem do pequeno cafeicultor, deve-se levar em conta não somente o tamanho, mas a capacidade de funcionar com regularidade para outros tipos de produtos. Segundo Silva et al. (2005), a pequena cafeicultura é também conhecida por produzir quantidades variáveis de tipos de grãos como arroz, feijão e milho.

Um outro problema que aparece no processo de secagem do café é a sua dificuldade de escoamento durante o início do processo inviabilizando, muitas vezes, a utilização de secadores dotados de dispositivos normais de movimentação dos grãos (helicóides e elevadores de canecas). Secadores equipados com mecanismos convencionais para o transporte de grãos não são recomendados para a secagem de café natural e descascado, quando estes apresentam teor de água acima de 40 \% b.u.. Recomendase, nesses casos, a pré-secagem em terreiros, em pré-secadores com ar aquecido (PINTO FILHO, 1994). Portanto, um secador com sistema de carga e revolvimento (helicóides, elevadores de canecas e pneumáticos) só pode produzir um café de qualidade se a matéria-prima, saída da pré-secagem (natural ou artificial), apresentar qualidade. Em outras palavras, não se pode melhorar a qualidade de um produto no secador, o que se pode fazer é mantê-la ou reduzir a intensidade de degradação.

Os transportadores pneumáticos usados em unidades armazenadoras tiveram origem nos equipamentos de pressão usados para carga e descarga de grãos em navios. Os transportadores pneumáticos movem os grãos, empregando-se uma corrente de ar em alta velocidade, através de um sistema de tubulação hermético. As aplicações de pneumáticos vão desde a movimentação de grãos em uma colhedora combinada, carga e descarga de navios, até no transporte de materiais sólidos na industrialização de cimento.

O ganho tecnológico, na área de pós-colheita do café, advindo das pesquisas, aliado ao desenvolvimento de novas tecnologias e processos mais eficientes e de simples utilização, juntamente a com sistemas de menor custo e maior eficiência de secagem e armazenagem têm permitido um salto de qualidade do produto, o que tem valorizado o café no concorrido mercado nacional e internacional. As racionalizações do uso da energia e dos impactos ambientais das práticas e tecnologias geradas são também desafios a serem vencidos para se alcançar a qualidade, a sustentabilidade e a competitividade do café brasileiro.

Diante do exposto, foi objetivo deste trabalho projetar, construir e avaliar um secador de fluxos concorrentes com carga, revolvimento e descarga pneumáticos, compatível com a produção e a capacidade de investimento da pequena produção para a secagem de café pergaminho. 


\section{Material e Métodos}

O experimento foi montado na Área de Pré-Processamento e Armazenamento de Produtos Vegetais do Departamento de Engenharia Agrícola da Universidade Federal de Viçosa - UFV.

Foram realizados quatro testes experimentais, sendo três testes com o secador operando com carga total e um teste o secador operando com carga reduzida. Pela impossibilidade de se obter médias entre os testes de sistemas de secagem por não haver repetições entre os mesmos, os resultados serão analisados considerando cada teste individualmente.

Foi utilizado o café cereja descascado da espécie Coffea arabica L., variedade Catuaí Vermelho. Após a colheita, feita pelo método derriça no chão, o produto foi submetido aos processos unitários de separação de impurezas, utilizando-se o peneiramento manual; separação hidráulica, para separação, de acordo com o estágio de maturação dos frutos; despolpamento/descascamento, para retirada da casca e de parte da mucilagem para posterior secagem; e, então, o café era encaminhado para um terreiro (dois dias) para perder água superficial. Após esses procedimentos, o produto era transportado para área experimental onde procederam-se os testes de secagem.

De cada teste, aproximadamente $10 \mathrm{~kg}$ de frutos foram secados ao sol, em lonas, para serem utilizados como testemunha.

O secador pneumático com capacidade para $2.500 \mathrm{~L}$ de café cereja descascado foi construído em módulos, para compor um "kit" de fácil transporte e montagem pelo usuário. Fazem parte do "kit": moega de homogeneização ou principal (módulo 1), conjunto de moegas (módulo 2), câmara de descanso/secagem (módulo 3a) e câmara de secagem (módulo 3b), coifa (módulo 4), duto de transporte pneumático (módulo 5), moega de recepção de grãos (módulo 6) e ventilador (Figura 1)

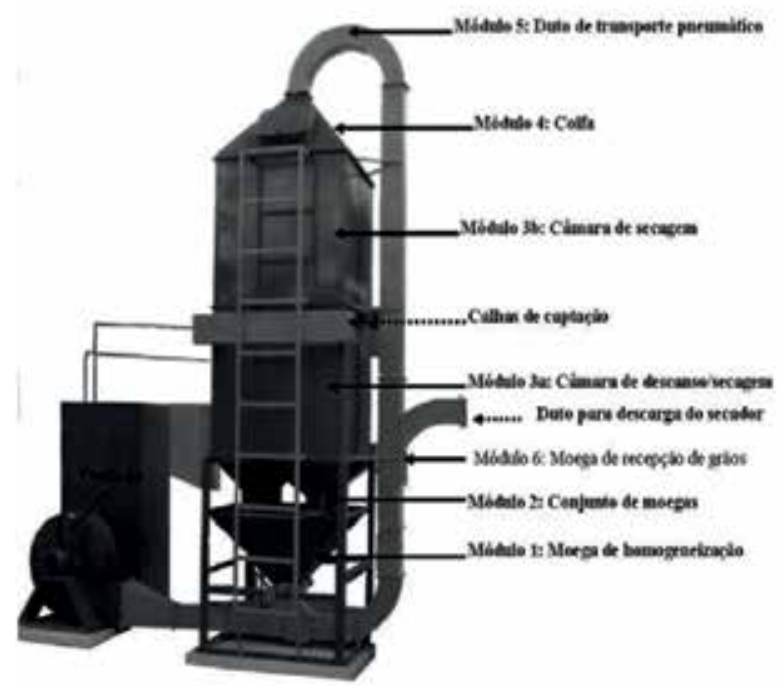

Figura 1 - Secador Pneumático de Fluxos Concorrente.

Fonte: Melo (2008)

Para avaliação do secador, a secagem foi realizada intermitentemente, ou seja, após sofrerem ação do ar aquecido, os grãos passavam por um período de descanso, durante intervalos de tempo pré-estabelecido. Esse processo foi realizado no decorrer da secagem até os grãos atingirem o teor de água de $15 \pm$ $2 \%$ b.u., para que a secagem fosse completada com ar natural no silo secador-armazenador.

As variáveis utilizadas para as análises dos sistemas de secagem foram propostas por Bakker-Arkema et al. (1978), porém só foram utilizados os parâmetros mais importantes, segundo Silva (2000). São elas: (i) temperatura e teor de água da massa de grãos; (ii) umidade relativa e temperatura do ar ambiente e de exaustão do secador; (iii) vazão de ar; (iv) tempo de secagem; (v) consumo energético; (vi) características qualitativas; e (vii) propriedades físicas do produto (inicial e final).

As medidas de temperatura do ar ambiente, do ar de secagem, do ar de exaustão, da massa de grãos na câmara de secagem, câmara de descanso/secagem e na moega de 
homonogeneização foram monitoradas. Para a medição da temperatura da massa de grãos, um cabo de aço foi posicionado verticalmente em seu interior, no qual foram fixados cinco termopares em intervalos de $0,40 \mathrm{~m}$, originando os pontos de medição $T_{0,40}, T_{0,80}, T_{1,20}, T_{1,60}$ e $\mathrm{T}_{2,0}$ (Figura 2).

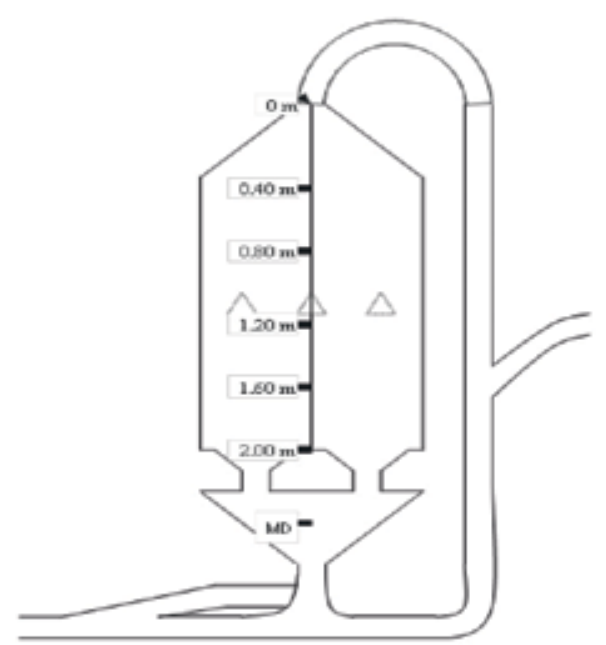

Figura 2 - Posicionamento dos sensores de temperatura no interior do secador.

Durante os testes de secagem, as determinações do teor de água dos grãos foram realizadas no momento do carregamento do secador, depois do revolvimento dos grãos, ou seja, de duas em duas horas e ao descarregar o secador. Para isso, foi utilizado o método EDABO (Evaporação Direta da Água em Banho de Óleo), uma variação do método de destilação com precisão semelhante ao método oficial da estufa (SAMPAIO, 2004).

Como a estufa é o método oficial, retiraram-se, também, amostras para a determinação do teor de água por esse método, utilizando-se a temperatura de $105 \pm 3^{\circ} \mathrm{C}$ durante 24 horas, com três repetições e com, aproximadamente, 30 gramas por amostra (BRASIL, 1992).

Para avaliar a vazão do ar de secagem foi utilizada a velocidade média do ar aquecido, cuja determinação baseou-se nas medidas das velocidades em 5 pontos da seção do duto de ventilação.

As massas inicial e final do café, para cada teste, antes de ir para o secador e/ou pré-secador, foram obtidas mediante pesagem em balança rodoviária da marca Filizola, com sensibilidade de leitura de $2 \mathrm{~kg}$. Para acompanhamento, as massas inicial e final dos lotes de café foram também obtidas indiretamente, utilizando-se relação entre a massa inicial e os teores de água final e inicial dos lotes de café.

Ao se aproximar do teor de água estabelecido para que o produto, de cada teste, fosse transferido para o silo secador, misturava-se em fluxo contínuo a massa de grãos e ensacava-se os grãos. Após o ensacamento, era feita a pesagem e o produto era transferido para silo secador, onde permanecia até atingir o teor de água para comercialização ( $11 \%$ b.u. $)$.

No silo secador-armazenador, acompanhou-se o teor de água da camada superior de grãos e, quando esses atingiam o teor de água de, aproximadamente, $11 \%$ b.u., indicando o fim do processo.

O consumo específico de energia foi determinado pelo balanço energético do ar.

O consumo de energia elétrica para o secador foi determinado a partir da potência nominal dos motores, fornecida no eixo, e o tempo de secagem, conforme Equação 1 (CAILLE, 1980; LACERDA FILHO e MELO, 2001).

$$
\mathrm{C}_{\mathrm{e}}=\frac{\text { Pot }_{\mathrm{n} \min \mathbf{a}} 736 \mathrm{t}}{\varepsilon}
$$

\section{em que}

$$
\begin{array}{lll}
\mathrm{C}_{\mathrm{ee}} & = & \begin{array}{l}
\text { consumo de energia } \\
\text { éétrica, } \mathrm{Wh} ;
\end{array} \\
\mathrm{Pot}_{\text {nominal }} & = & \text { potência nominal, } \mathrm{CV} ; \\
\mathrm{E} & = & \begin{array}{l}
\text { rendimento do motor } \\
\text { éétrico, decimal. }
\end{array}
\end{array}
$$

Para análise do tipo do café e da qualidade de bebida, foram enviadas amostras de $300 \mathrm{~g}$ de café beneficiado, seco ao sol (testemunhas) e seco no secador pneumático, para a Corretora de Café Três Irmãos Ltda., localizada em Viçosa - MG, onde foram realizadas análise sensorial e classificação do café.

\section{Resultados e Discussão}

Os resultados experimentais das condições iniciais e finais do produto, quantidade de água removida, tempo de secagem, capacidade de secagem e taxa de secagem, utilizados nos testes são apresentados na Tabela 1. 
Tabela 1 - Parâmetros relativos aos grãos

\begin{tabular}{|c|c|c|c|c|c|c|c|c|c|}
\hline \multicolumn{2}{|c|}{ Teste Inicial } & \multicolumn{2}{|c|}{$\begin{array}{c}\text { Massa de grãos } \\
(\mathrm{kg})\end{array}$} & \multicolumn{2}{|c|}{$\begin{array}{l}\text { Teor de água dos } \\
\text { grãos (\%) }\end{array}$} & \multirow{2}{*}{$\begin{array}{l}\text { Quantidade } \\
\text { de água } \\
\text { removida } \\
\text { (Horas) }\end{array}$} & \multirow{2}{*}{$\begin{array}{l}\begin{array}{l}\text { Tempo de } \\
\text { secagem }\end{array} \\
\left(\mathrm{kg} \mathrm{h}^{-1}\right)\end{array}$} & \multirow{2}{*}{$\begin{array}{l}\begin{array}{l}\text { Capacidade } \\
\text { de secagem }\end{array} \\
\left(\mathrm{kg}_{\mathrm{H} 2 \mathrm{O}} \mathrm{h}^{-1}\right)\end{array}$} & \multirow[t]{2}{*}{$\begin{array}{l}\text { Taxa de } \\
\text { secagem }\end{array}$} \\
\hline & & Final & Inicial & Final & (kg de água) & & & & \\
\hline FT1 & 1320 & 950 & 37,5 & 13 & 372 & 23 & 57,4 & 16,1 & \\
\hline FT2 & 1130 & 936 & 30 & 15 & 194 & 16 & 70,6 & 12,1 & \\
\hline FT3 & 938 & 723 & 30 & 13 & 180 & 16 & 58,6 & 11,2 & \\
\hline FTM4 & 620 & 523 & 31 & 17 & 111 & 11 & 56,4 & 9,1 & \\
\hline
\end{tabular}

Os resultados experimentais das condições do ar ambiente, do ar de secagem e do ar de exaustão, assim como a umidade relativa e a vazão do ar de secagem, para cada teste, são apresentados na Tabela 2. As condições experimentais observadas referem-se a valores médios oriundos de registros, realizados a intervalos regulares de 10 minutos.

Tabela 2 - Valores médios relativos ao ar ambiente, ao ar de secagem e ao ar de exaustão

\begin{tabular}{llllllll}
\hline \multirow{2}{*}{ Teste } & $\begin{array}{c}\text { Vazão do ar } \\
\left(\mathrm{m}^{3} \mathrm{~min}^{-1}\right)\end{array}$ & \multicolumn{3}{c}{ Temperatura média do ar $\left({ }^{\circ} \mathrm{C}\right)$} & \multicolumn{3}{c}{ Umidade relativa do ar (\%) } \\
\hline & & Ambiente & Secagem & Exaustão & Ambiente & Secagem & Exaustão \\
FT1 & $24 \pm 1,6$ & $59 \pm 5,1$ & $28 \pm 6,0$ & $61 \pm 7,4$ & $10 \pm 0,8$ & $78 \pm 18,9$ \\
FT2 & $23,2 \pm 0,6$ & $24 \pm 1,2$ & $55 \pm 4,0$ & $35 \pm 4,9$ & $59 \pm 5,1$ & $11 \pm 0,8$ & $56 \pm 19,9$ \\
FT3 & & $23 \pm 1,8$ & $61 \pm 2,4$ & $33 \pm 5,6$ & $61 \pm 8,2$ & $8 \pm 0,3$ & $67 \pm 21,1$ \\
FTM4 & $33,4 \pm 0,8$ & $24 \pm 2,2$ & $24 \pm 2,2$ & $29 \pm 3,3$ & $58 \pm 5,3$ & $13 \pm 4,7$ & $44 \pm 10,5$
\end{tabular}

Os valores experimentais médios da temperatura do ar de secagem e temperatura da massa de grãos nos pontos de medição, nas câmaras de secagem e descanso podem ser observados na Tabela 3 .

Tabela 3 - Temperatura do ar de secagem e da massa de grãos nas câmaras de secagem, descanso e moega de descanso, valores médios

*Camada de grãos abaixo da posição do sensor de temperatura.

\begin{tabular}{|c|c|c|c|c|c|c|c|}
\hline \multirow{3}{*}{ Teste } & \multirow{3}{*}{$\begin{array}{l}\text { Temperatura } \\
\text { média do ar de } \\
\text { secagem }\left({ }^{\circ} \mathrm{C}\right)\end{array}$} & \multicolumn{6}{|c|}{ Temperatura média da massa de café $\left({ }^{\circ} \mathrm{C}\right)$} \\
\hline & & \multicolumn{2}{|c|}{ Câmara de secagem } & \multicolumn{3}{|c|}{ Câmara de descanso } & $\begin{array}{l}\text { Moega de } \\
\text { descanso }\end{array}$ \\
\hline & & $0,40 \mathrm{~m}$ & $0,80 \mathrm{~m}$ & $1,20 \mathrm{~m}$ & $1,60 \mathrm{~m}$ & $2,00 \mathrm{~m}$ & \\
\hline FT1 & $59 \pm 5,1$ & $44 \pm 11,5^{*}$ & $33 \pm 7,9$ & $29 \pm 6,4$ & $28 \pm 6,1$ & $26 \pm 6,1$ & $26 \pm 5,7$ \\
\hline FT2 & $55 \pm 4,0$ & $33 \pm 7,0$ & $33 \pm 5,2$ & $34 \pm 5,3$ & $28 \pm 3,1$ & $27 \pm 2,5$ & $26 \pm 3,5$ \\
\hline \multirow[t]{2}{*}{ FT3 } & $61 \pm 2,4$ & $57 \pm 4,9 *$ & $36 \pm 7,6$ & $33 \pm 7,3$ & $30 \pm 3,0$ & $28 \pm 3,6$ & $28 \pm 2,0$ \\
\hline & & & \multicolumn{5}{|c|}{ Câmara de secagem } \\
\hline FTM4 & $52 \pm 7,2$ & - & - & $33 \pm 9,8$ & $34 \pm 8,3$ & $27 \pm 5,8$ & $26 \pm 6,2$ \\
\hline
\end{tabular}


Na Tabela 3, observa-se que a temperatura média da massa de grãos não ultrapassou $45^{\circ} \mathrm{C}$. Observa-se, ainda, que a temperatura média da massa de grãos situada a $0,40 \mathrm{~m}$ da entrada do ar de secagem, na maioria dos testes, foi superior às temperaturas nas demais camadas.

A temperatura da massa de grãos na câmara de descanso sempre foi inferior aos valores atingidos pela massa de grãos durante a secagem. Observou-se um decréscimo na temperatura da massa de grãos, em relação à proximidade com conjunto de quatro moegas, possibilitando maior redução na temperatura dos grãos. Em relação à temperatura da massa de grãos contida na moega de descanso, observaram-se valores próximos à temperatura do ar ambiente.

Na Tabela 4, são apresentados os valores experimentais do consumo de energia teórico total, ou seja, energia térmica e elétrica e o consumo específico total de energia no secador pneumático.

Tabela 4 - Resultado do consumo total de energia (térmica e elétrica) no secador pneumático

\begin{tabular}{|c|c|c|c|}
\hline Teste & Consumo total de energia (MJ) & $\begin{array}{l}\text { Massa de água } \\
\text { evaporada (kg de } \\
\text { água evaporada) }\end{array}$ & $\begin{array}{c}\text { Consumo específico total } \\
\text { de energia }\left(\mathrm{kJ} \mathrm{kg}^{-1} \text { de água }\right. \\
\text { evaporada) }\end{array}$ \\
\hline
\end{tabular}

\begin{tabular}{lllll}
\hline & Térmica & Elétrica & & \\
FT1 & 1.118 & 216 & 371 & 3.596 \\
FT2 & 754 & 150 & 194 & 4.660 \\
FT3 & 829 & 150 & 180 & 5.439 \\
FTM4 & 683 & 103 & 110 & 7.145
\end{tabular}

Na Tabela 4, observa-se que os valores de consumo específico de energia térmica, para o teste com o secador operando com meia carga foi muito superior aos obtidos nos demais testes. Tal fato ocorre, pois, ao passar pela massa de grãos, o ar ainda possui potencial para secagem, sendo perdido para o ambiente.

Quanto ao consumo específico de energia para esse tipo de secador, segundo Thompson, citado por OSÓRIO (1982), deve estar na faixa de 4.185 a $5.120 \mathrm{~kJ} \mathrm{~kg}^{-1}$ de água evaporada. Como se pode perceber que o consumo específico médio de energia observado foi inferior aos valores citados por Thompson, sendo considerados muito bons. Vale ressaltar que, nos cálculos, não foi computada a eficiência térmica do sistema de aquecimento do ar, que varia conforme o tipo de sistema empregado, nem energia consumida pelo motor do ventilador.

As amostras de café cereja descascado foram enviadas a Três Irmãos Corretora de Café em Viçosa, onde foram feitas as análises sensorial e de classificação do café, para avaliação da qualidade da bebida e das características dos grãos. Os resultados são apresentados na Tabela 5.

Tabela 5 - Resultados da classificação do café

\begin{tabular}{lllllll}
\hline \multicolumn{1}{c}{ Testes } & \multicolumn{1}{c}{ Bebida } & Tipo & Aroma & Aspecto & Defeitos & Renda \\
\hline FT1 & Apenas mole & $5 / 15$ & Bom & Bom & 42 & 300x243 (81\%) \\
Testemunha 3 & Mole & $5 / 15$ & Bom & Bom & 57 & 300x242(81\%) \\
FT2 & Apenas mole & $5 / 15$ & Bom & Bom & 57 & $300 \times 240(80 \%)$ \\
Testemunha 5 & Apenas mole & $5 / 20$ & Bom & Bom & 60 & $300 \times 237(79 \%)$ \\
FT3 & Apenas mole & $4 / 45$ & Bom & Bom & 45 & $300 \times 232(77 \%)$ \\
Testemunha 8 & Mole & $5 / 5$ & Bom & Bom & 48 & $300 \times 243(81 \%)$ \\
FTM4 & Apenas mole & $5 / 15$ & Bom & Bom & 57 & $300 \times 230(77 \%)$ \\
Testemunha 6 & Apenas mole & $5 / 10$ & Bom & Bom & 54 & $300 \times 228(76 \%)$
\end{tabular}


Por meio dos resultados obtidos na classificação, que podem ser observados na Tabela 5 , os lotes de café utilizados no novo sistema de secagem foram considerados de ótima qualidade, para as condições de produção na região da Zona da Mata Mineira, sendo classificados como de bebida mole e apenas mole.

Na Tabela 5, observa-se que a qualidade da bebida dos cafés não foi influenciada pelo combustível utilizado (lenha), principalmente em função do uso do sistema de aquecimento indireto do ar de secagem, sem qualquer contato com fagulhas ou fumaça com as massas de grãos submetidas ao processo de secagem. Outro fator que colaborou para a qualidade obtida foi a temperatura da massa de grãos, que não ultrapassou $45^{\circ} \mathrm{C}$ em nenhum teste.

Considerando que o tipo " 4 " e " 6 " é tido como padrão para exportação, pode-se dizer que, neste estudo, o produto apresentou resultados satisfatórios com tipo " 5 " na maioria dos testes realizados (Tabela 5).

Em relação ao aroma e aspecto, os resultados obtidos nos testes foram os mesmos obtidos nas testemunhas. Os itens aroma e aspecto apresentaram-se bom com bebida apenas mole e mole, difícil de obter na secagem em altas temperaturas, em razão da desuniformidade na secagem.

No item número de defeitos, os resultados obtidos nos testes foram próximos aos da testemunha, que foram secadas ao sol. Esse resultado indica que o processo de secagem não interferiu no número de defeitos.
A variável renda estabelece a relação entre a massa de frutos secos e a massa de grãos beneficiados. Observou-se que os valores obtidos nos testes foram bem próximos aos obtidos com as testemunhas, indicando que o novo processo de secagem não influenciou o rendimento.

\section{Conclusões}

De acordo com os resultados obtidos nos testes realizados, pode-se concluir que:

- o protótipo apresentou consumo específico total de energia abaixo dos limites de consumo previstos na literatura para esse tipo de secador;

- no teste em que o secador pneumático operou com meia carga, FTM4, o consumo específico médio de energia foi superior aos demais testes, mostrando-se ser operável com carga inferior para a qual foi dimensionado;

- quanto às características relacionadas aos danos mecânicos, que podem ser causados pelo impacto promovido pelo sistema pneumático, foi observado que não ocorreram danificações nem injúrias ao produto;

- o café processado no novo secador apresentou boa qualidade quanto ao tipo e bebida;

- o secador é facilmente operado durante o carregamento, secagem e descarga, além de requerer pouca manutenção e mão-de-obra; $\mathrm{e}$

- é flexível, funciona eficientemente com a quantidade de café disponível. 


\section{Referências}

1. BAKKER-ARKEMA, F. W.; LEREW, L. E.; BROOK, R.C.; BROOKER, D.B. Energy and capacity performance avaluation of grain dryer. Transactions of the ASAE, St. Joseph, 1978. $13 \mathrm{p}$.

2. BRASIL, Ministério da agricultura e da Reforma Agrária. Regras para análise de sementes (RSA). Brasília, 1992. 365 p.

3. CAILLE, R. E. Aparelhos elétricos: potências, demandas consumos, produções. São Paulo: CESP. 1980. 64p.

4. LACERDA FILHO, A.F.; MELO, E. C. Tecnologias de Produção de Café com Qualidade. Viçosa, Laércio Zambolil, p.527-564, 2001.

5. MACHADO, M. C.; SAMPAIO, C. P., SILVA, J.S. Avaliação técnico-econômica do processamento de café: secagem completa em terreiros. In: SIMPÓSIO DE PESQUISAS DOS CAFÉS DO BRASIL E WORKSHOP INTERNACIONAL DE CAFÉ \& SAÚdE, (3.:2003, Porto Seguro). Anais.... Brasília, DF: Embrapa Café, 2003b. (447 p.).

6. MELO, F. A. O. Desenvolvimento e avaliação de um secador de fluxos concorrentes, com carga, revolvimento e descarga pneumáticos. Viçosa: UFV, 2008, 122 p. Dissertação (Doutorado em Engenharia Agrícola) - Universidade Federal de Viçosa, 2008.
7. OSÓRIO, A G. S. Projeto e construção de um secador intermitente de fluxos .; Iconcorrentes e sua avaliação na secagem de café. Viçosa, MG: UFV, 1982. 57p. Dissertação (Mestrado em Engenharia Agrícola) - Universidade Federal de Viçosa, 1982.).

8. PINTO FILHO, G.L. Desenvolvimento de um secador de fluxos cruzados com reversão do fluxo de ar de resfriamento, para a secagem de café (Coffea arábica L.). Viçosa, MG: UFV, 1993. 72p. Dissertação (Mestrado em Engenharia Agrícola) - Universidade Federal de Viçosa, 1994.

9. SAMPAIO, C. P. Desenvolvimento de um secador com reversão do fluxo de ar com sistema de movimentação pneumática de grãos. Viçosa: UFV, 2004, 97p. Dissertação (Doutorado em Engenharia Agrícola) - Universidade Federal de Viçosa, 2004.

10. SILVA, J. S.; LUCENA, E. M. P. Estrutura, composição e propriedades dos grãos. In: Pré-Processamento de produtos agrícolas. Editado por Juarez de Sousa e Silva- Juiz de Fora, MG. Instituto Maria, 2000. 21-37p.

11. SILVA, J.S.; NOGUEIRA, R.M.; ROBERTO, C.D. Tecnologia de secagem e armazenagem para a agricultura familiar. Viçosa - MG. 2005. 138p.

Endereço para Correspondência:

Fernanda Augusta de Oliveira Melo fernanda.melo@foa.org.br Centro Universitário de Volta Redonda - UniFOA Campus Olezio Galotti Av. Paulo Erlei Alves Abrantes, no 1325 Três Poços - Volta Redonda - RJ CEP: 27240-000 